\title{
Biowaste-Derived Humic-like Substances Improve Growth and Quality of Orange Jasmine (Murraya paniculata L. Jacq.) Plants in Soilless Potted Culture
}

\author{
Giancarlo Fascella $^{1, *}$, Enzo Montoneri ${ }^{2}$ and Youssef Rouphael $^{3}$ (D) \\ 1 CREA Research Centre for Plant Protection and Certification, 90011 Bagheria, Italy \\ 2 Dipartimento di Scienze delle Produzioni Agrarie e Alimentari, Università di Catania, Via S. Sofia 98, \\ 95123 Catania, Italy; enzo.montoneri@gmail.com \\ 3 Department of Agricultural Sciences, University of Naples Federico II, 80055 Portici, Italy; \\ youssef.rouphael@unina.it \\ * Correspondence: giancarlo.fascella@crea.gov.it
}

\section{check for} updates

Citation: Fascella, G.; Montoneri, E.; Rouphael, Y. Biowaste-Derived Humic-like Substances Improve Growth and Quality of Orange Jasmine (Murraya paniculata L. Jacq.) Plants in Soilless Potted Culture. Resources 2021, 10, 80. https:// doi.org/10.3390/resources10080080

Academic Editors: Ezio Riggi, Raffaella Maria Balestrini and Edoardo Marco Napoli

Received: 24 June 2021

Accepted: 3 August 2021

Published: 8 August 2021

Publisher's Note: MDPI stays neutral with regard to jurisdictional claims in published maps and institutional affiliations.

Copyright: (C) 2021 by the authors. Licensee MDPI, Basel, Switzerland. This article is an open access article distributed under the terms and conditions of the Creative Commons Attribution (CC BY) license (https:/ / creativecommons.org/licenses/by/ $4.0 /)$.

\begin{abstract}
Humic-like substances (HLS) are among the most used biostimulants in agriculture as a means for improving plant growth, nutrient uptake, crop yield, and stress tolerance. HLS derived from municipal biowastes were applied as a substrate drench in order to evaluate their biostimulatory effect on the growth and ornamental quality of Orange Jasmine (Murraya paniculata L. Jacq.) potted plants. Two HLS, derived from the digestion of the organic humic fraction and from composting of a mix of sewage sludge digestate and gardening residues, were compared with a commercial leonardite-based product in the framework of a greenhouse experiment in soilless culture. The application of the two biowaste-derived HLS resulted in plants showing a 39.9\%, 87.0\%, $111.6 \%, 35.4 \%, 37.9 \%, 35.3 \%$, and $81.3 \%$ increase in plant height, number of flowers and fruits, leaf production, total dry biomass, root length, and water use efficiency, respectively, compared to those treated with the commercial product and the untreated (control) plants. The enhanced growth performance of HLS-treated plants was due to the higher chlorophyll relative content $(+24.2 \%$ on average) and net photosynthesis $(+114.7 \%$ on average) of their leaves. The positive results obtained from the application of non-commercial HLS suggest that biowaste recycling is a sustainable and environment-friendly source of biostimulants, as an alternative to agrochemicals and existing leonardite-based plant biostimulants.
\end{abstract}

Keywords: plant biostimulants; humic acids; leonardite; urban biowastes; digestate; compost; ornamentals; photosynthesis

\section{Introduction}

Scientific and technical innovation has advanced many agricultural products, with improvements in plant growth, yield, and quality, as well as in the interaction between plant and soil/growing substrates. All this has indirectly increased tolerance/resistance against environmental stressors [1,2]. Some of these products, often defined as biostimulants, includes a wide range of organic substances able to increase biological processes at both the plant or rhizo-level [3,4]. Plant biostimulants are usually described as substances (e.g., humic substances, seaweed extracts, and protein hydrolysates) and/or micro-organisms (arbuscular mycorrhizal fungi and plant growth-promoting rhizobacteria) that, when applied to plants and/or to the rhizosphere, stimulate physiological and molecular mechanisms that boost quality attributes, root growth, nutrient uptake, tolerance to abiotic stresses, with positive effects on plant biomass, seed setting, flowers, and fruits production [5-9].

Biostimulants are generally used for high-profit horticultural crops such as greenhousegrown vegetables and ornamental plants. These are often cultivated in soilless systems [1,7]. Humic-like substances (HLS) are among the most employed organic non-microbial plant biostimulants. HLSs can be extracted from natural fossil sources like peat and leonardite, 
and from decayed organic material like compost and digestate [4,10-12]. HLSs are condensate organic compounds or macromolecules with a complex molecular structure and high soil/substrate tenacity $[13,14]$. They show both a hydrophilic and a hydrophobic fraction, with the latter containing humic acids and fulvic acids [15-17].

HLSs seem to be able to increase lateral root elongation, in addition to micro- and macronutrients uptake, according to the so-called "auxin-like effect" mechanism [18-20]. The higher absorption of some micronutrients by plant roots treated with HLSs is due to chelation but also to the permeability increase of the plasmatic membrane, which determines a higher root capacity to uptake nutrients from the soil solution [19,21]. Moreover, the alteration of substrate-plant-microbiota interactions affects the number of chemical compounds in plant cells such as those associated with C-N-P cycles and photosynthesis, thus determining important biochemical changes to primary and secondary metabolisms [22,23]. HLSs may significantly affect many plant physiological processes through the increase of cation exchange and water retention capacities, the modification of the absorption kinetics and ion transportation, and chlorophyll and nucleic acids biosynthesis [24-26]. Recently, an increasing interest of growers and industries towards HLSs have been recorded, because of their multiple positive outcomes on plant growth and quality.

Besides peat and/or leonardite extraction, HLSs may be obtained from organic residues like compost or digestate [14]. Digestates are the liquid/slurry by-product of the anaerobic digestion of organic matter and are rich in organic residues [4]. HLSs may be produced through aerobic composting of organic matter from bio-waste under thermophilic conditions. During this process, raw organic material is transformed by microorganisms into more stable materials such as humic substances as a result of biological product heat [27-29]. For these reasons, digestate and compost are generally used for the extraction of valued soluble organic compounds such as HLSs and bio-based soluble substances (SBO), which may be successfully employed in horticulture [12,14,30-33].

Orange Jasmine (Murraya paniculata L. Jacq; Rutaceae family) is an evergreen, up to 3-4 m high shrub, spread throughout Southeast Asia and Northeast Australia. This species, also known as false citrus, is used for ornamental purposes (mainly as a hedge plant) for its glossy dark-green leaves and large clusters of white-orange blossom scented flowers, and small bright red berries $[34,35]$. Orange Jasmine is available at commercial nurseries throughout the world and some growing protocols have been recently defined for south Mediterranean areas characterized by water scarcity and soil salinization $[30,36,37]$. To our knowledge, information regarding the application of biostimulants on Murraya plants is not available. Therefore, to evaluate the effect of HLS as a plant biostimulant for ornamental species in soilless culture, Orange Jasmine potted plants were treated with two HLS obtained from municipal bio-waste (one deriving from the digestion of organic humic fraction and the other from a compost mixture of sewage sludge, digestate, and gardening residues) along with a commercial leonardite-based product. The scope of the study was to determine the influence of different HLSs on Orange Jasmine's growth, ornamental quality, plant biomass production and partitioning, water use efficiency, and eco-physiological activities.

\section{Materials and Methods}

\subsection{Biowaste-Derived and Commercial Humic-like Substances}

The two non-commercial HLS were produced through the hydrolysis of different fermented urban biowaste materials [14]. The first non-commercial HLS was represented by the anaerobic digestate (Digest HLS) of the organic humid fraction of urban waste coming from separate source collections. The second biowaste-derived HLS was the compost (Comp HLS) achieved from a mixture of sewage sludge, Digested HLS, and urban gardening residues (1:3.5:5.5 $w / w / w)$ aged for 110 days under aerobic conditions. The commercial HLS was a leonardite-based product (Leonar HLS), officially named "Enersoil" and purchased from an Italian enterprise (Intrachem Bio, Bergamo, Italy). The main chemical characteristics of the three HLS are reported in Table 1: $\mathrm{pH}, \mathrm{C}$, and $\mathrm{N}$ content, $\mathrm{C} / \mathrm{N}$ ratio as well as macro 
and micronutrients concentration. The latter of the non-commercial HLS were determined according to the analytical procedures reported in previous studies [12], whereas the nutrient content of commercial HLS is based on the package's label reported by the vendor.

Table 1. Chemical composition of commercial leonardite-based and biowaste-derived (digestate and compost) humic-like substances (HLS).

\begin{tabular}{|c|c|c|c|c|c|c|c|c|c|c|c|c|}
\hline & $\mathrm{pH}$ & C & $\mathrm{N}$ & $\mathrm{C} / \mathrm{N}$ & $\mathrm{P}_{2} \mathrm{O}_{5}$ & K & $\mathrm{Ca}$ & Mg & $\mathrm{Fe}$ & $\mathrm{Na}$ & $\mathrm{Cu}$ & $\mathrm{Zn}$ \\
\hline Leonar HLS & $9.9 \pm 0.2$ & $29.8^{\mathrm{a}} \pm 0.5$ & $0.22 \pm 0.01$ & $135.4 \pm 2.0$ & $0.52^{b} \pm 0.02$ & $4.89 \pm 0.03$ & $0.41 \pm 0.04$ & $0.39 \pm 0.02$ & $0.10 \pm 0.01$ & $3.10 \pm 0.06$ & $2.96 \pm 0.05$ & $2.50 \pm 0.06$ \\
\hline Digest HLS & $6.4 \pm 0.3$ & $45.1 \pm 0.1$ & $7.87 \pm 0.1$ & $5.73 \pm 0.4$ & $1.16 \pm 0.01$ & $9.15 \pm 0.08$ & $1.32 \pm 0.06$ & $0.18 \pm 0.01$ & $0.16 \pm 0.02$ & $0.39 \pm 0.02$ & $100 \pm 1.3$ & $185 \pm 2.6$ \\
\hline Comp HLS & $8.2 \pm 0.5$ & $35.1 \pm 0.1$ & $4.34 \pm 0.2$ & $8.10 \pm 0.3$ & $1.45 \pm 0.02$ & $5.49 \pm 0.05$ & $2.59 \pm 0.05$ & $0.49 \pm 0.02$ & $0.58 \pm 0.02$ & $0.15 \pm 0.01$ & $216 \pm 2.3$ & $353 \pm 4.7$ \\
\hline
\end{tabular}

${ }^{a}$ Values refer to dry matter: The means and standard deviations are calculated over triplicates. ${ }^{\mathrm{b}} \mathrm{P}_{2} \mathrm{O}_{5}, \mathrm{~K}, \mathrm{Ca}, \mathrm{Mg}, \mathrm{Fe}, \mathrm{Na}$ as $\% w / w$. $\mathrm{Cu}$ and $\mathrm{Zn}$ as $\mathrm{mg} / \mathrm{kg}$.

\subsection{Tested Plant and Growing Conditions}

The study was accomplished during the 2017 growing season (from March to July) at a private nursery located in Marsala $\left(37^{\circ} 73^{\prime} \mathrm{N}, 12^{\circ} 54^{\prime} \mathrm{E}, 10 \mathrm{~m}\right.$ a.s.l.), near Trapani, NW Sicily. Five-month-old Orange Jasmine (Murraya paniculata L. Jacq cv.exotica) plants were transferred from plug-trays to $1.5 \mathrm{~L}$ volume-polyethylene pots $(16 \mathrm{~cm}$ diameter, 1 plant/pot) filled with a commercial substrate (Completo, Vigorplant Italia srl, Fombio, Italy) composed by a mixture of Irish and Baltic peats $(0-20 \mathrm{~mm})$ and volcanic pumice $(3-8 \mathrm{~mm})$ in $4: 1 \mathrm{v} / \mathrm{v}$ ratio. Potted plants were grown for 4 months in an unheated $\left(28^{\circ} \mathrm{C}\right.$ day $/ 14{ }^{\circ} \mathrm{C}$ night $)$ single-span greenhouse $\left(200 \mathrm{~m}^{2}\right)$. Irrigation was provided to the plants by means of an automated drip system ( 1 dripper per pot, $2 \mathrm{~L} \mathrm{~h}^{-1}$ ). The same nutrient solution, whose chemical composition has been already reported [11], was supplied to all Murraya plants while maintaining the $\mathrm{pH}$ at 6.0 and the electrical conductivity at $2.0 \mathrm{mS} \mathrm{cm}^{-1}$. Fertigation management was accomplished by electronic low-tension tensiometers (LT-Irrometer, Riverside, CA, USA). The leonardite-based product and the two non-commercial HLS were dissolved/diluted in water in order to have three solutions with the subsequent dry matter concentrations: 18.7, 31.0, and $45.5 \mathrm{~g} \mathrm{~L}^{-1}$, for Leonar HLS, Digest HLS, and Comp HLS, respectively. A $100 \mathrm{~mL}$ aliquot of each solution was applied to every single plant as substrate drench. Plant drenching treatments were carried out twice (15 and 60 days after planting) throughout the experiment (120 days). HLSs were supplied to the plants by drenching because a preliminary study on other ornamental species [11] evidenced that their application by foliar spraying resulted in dark-stained leaves with negative effects on photosynthesis and aesthetic values. Total supplied amounts of dry matter plant $^{-1}$ were 2.0, 3.1 and $4.5 \mathrm{~g} \mathrm{plant}^{-1}$ for Leonar HLS, Digest HLS, and Comp HLS, respectively. The study was completed four months after planting when potted Orange Jasmine reached the marketable size.

\subsection{Plant Growth Measurement}

With the aim to assess the effect of the HLS typology on Murraya's growth and quality, twelve plants per treatment were randomly collected every 40 days and split into stems, leaves, and roots for growth measurements. Biomass production was determined by freshly weighing each plant tissue/organ and successively drying it in a forced-air oven (at $90{ }^{\circ} \mathrm{C}$ for $72 \mathrm{~h}$ ) until a constant weight was reached. The root-to-shoot $(\mathrm{R} / \mathrm{S})$ ratio was calculated as follows: root dry weight/(leaf + stem dry weight). Plant height was measured with a ruler as the distance from the substrate surface to the top of the plant. The number of stems, flowers, fruits, and leaves of each plant was assessed. Total leaf area (LA) was determined by means of a digital area meter (WinDIAS 2; DELTA-T DEVICES Ltd., Cambridge, UK). The maximum root length consisted of the measurement carried out between the end of the longest root and the base of the stem. Water Use Efficiency (WUE) was assessed as the plant's total dry weight/water supply [11,12]. 


\subsection{Leaf SPAD Index, Color Coordinates, Gas Exchanges Measurement and Total Chlorophyll Content}

Relative chlorophyll content of the leaves, expressed as the SPAD index, was measured on ten randomly selected and fully expanded leaves per replicate using a portable chlorophyll meter SPAD-502 (Konica-Minolta corporation, Ltd., Osaka, Japan). On the same leaves, the color space coordinates: $\mathrm{L}^{*}$ (lightness), $\mathrm{a}^{*}$ (redness/greenness), $\mathrm{b}^{*}$ (yellowness/blueness), as well as the Chroma (saturation) and Hue angle were assessed through measurement in the middle of the lamina using a chromameter (Minolta CR-300, Konica Minolta, Osaka, Japan) which was previously calibrated with a standard white plate before sampling. Leaf gas exchanges [net photosynthesis (Pn) and stomatal conductances (Gs)] were also measured on five fully-expanded leaves per replicate on a sunny day, between 11:00 and 14:00 h, by means of a portable photosynthesis system (LI-6200; LI-COR Inc., Lincoln, NE, USA) equipped with a stirred leaf chamber containing constant-area inserts and fitted with an adjustable intensity red source. The leaf concentration of total chlorophylls ("a $+b^{\prime \prime}$ ) was determined following the method reported by D'Angiolillo et al. (2018) [38]. Fresh leaf samples (200 mg), randomly harvested from plants subjected to the four treatments, were extracted overnight in pure methanol $(5 \mathrm{~mL})$ at $4{ }^{\circ} \mathrm{C}$ in the dark. Absorbance of the leaf extracts at 665, 652, and $470 \mathrm{~nm}$ were measured using a UV/Vis spectrophotometer (Beckman DU 530, Life Science, Ramsey, MN, USA).

\subsection{Experimental Design and Data Analysis}

A completely randomized block design was adopted for this experiment. The four treatments [the three HLS typologies and the control (untreated plants)] were replicated three times with 20 potted plant replicates ${ }^{-1}$ (60 plants per treatment). Data collected from the present experiment were subjected to a one-way analysis of variance (ANOVA). Statistical significance was determined at the $p=0.05$ level using Tukey's HSD test, through the use of the Statistica (Statsoft Inc., Tulsa, OK, USA) software package. The variability of the bio-morphological and eco-physiological data among HLS typologies was evaluated by means of principal component analysis (PCA); this analysis was performed using the Paleontological Statistics (PAST, version 3.25, Oslo, Norway) software package.

\section{Results}

\subsection{Chemical Characteristics of Leonardite-Based and Biowaste-Derived HLS}

Table 1 reports the composition of the commercial leonardite-based HLS (Leonar HLS) and the two non-commercial biowaste-derived Digest and Comp HLS. Both noncommercial HLS were characterized by higher $\mathrm{C}$ and $\mathrm{N}$ content than those measured in Leonar HLS and, consequently, by a lower $\mathrm{C} / \mathrm{N}$ ratio (6.9 on average), with respect to that calculated for Leonar HLS (135.4). The different $\mathrm{C} / \mathrm{N}$ ratios are not surprising. The Digest HLS was obtained from the digestate of unsorted food wastes from a separate collection. The high nitrogen content derives from the high protein content in the pristine food waste. The Comp HLS was obtained from a pristine biowaste mix containing green residues with low $\mathrm{N}$ content. This explains the higher $\mathrm{C} / \mathrm{N}$ ratio of Comp HLS, compared to Digest HLS. On the other hand, Leonar HLS derives from a fossil carbon material. Fossil carbon and oil have low or no $\mathrm{N}$ content, as a result of long-term degradation leading to the loss of organic $\mathrm{N}$ and $\mathrm{O}$ in the form of the most thermodynamically stable $\mathrm{N}_{2}, \mathrm{O}_{2}, \mathrm{NH}_{3}$, and $\mathrm{CO}_{2}$ gases.

Also, the mineral elements' content of the two non-commercial HLS was higher than that of Leonar HLS. Compost HLS had higher mineral elements' content than Digest HLS, except for $\mathrm{K}$ and $\mathrm{Na}$ that were higher in the latter.

The Leonar HLS dose favored by the vendor to be administrated to the plants ranged from 5 to $20 \mathrm{~kg} \mathrm{ha}^{-1}$ for soilless cultivation use. As the commercial product and the two biowaste-derived HLS had different chemical compositions (Table 1), to compare the three products for their effects on plant performance different doses of products were applied according to two different criteria. The first criterion was commercial. Plant nurseries evaluate and compare products based on the product cost per unit weight and the obtained 
plant performance. Thus, Leonar HLS was applied at the dose suggested by the vendor, and Comp HLS was applied at the same weight dose. Considering the different physical forms of the two products, dense liquid for Leonar HLS and solid for Comp HLS, the applied doses per plant were $6 \mathrm{~g}$ for Leonar HLS and $5 \mathrm{~g}$ equivalent dry matter for Comp HLS. The second criterion was mainly scientific. The objective was to compare the effects of the two biowaste-derived HLS as a function of their chemical composition. Thus, the applied Digest HLS dose was $3.2 \mathrm{~g} \mathrm{plant}^{-1}$. Considering the $5 \mathrm{~g} \mathrm{plant}^{-1}$ Comp HLS applied dose, the $\mathrm{N}$ and $\mathrm{C}$ applied dose resulted in 0.20 and $0.25 \mathrm{~N} \mathrm{~g}$ plant $^{-1}$ and 1.3 and $1.8 \mathrm{C} \mathrm{g}$ plant $^{-1}$, respectively, contributed from the Digest and Comp HLS. This approach allowed comparing the two biowaste-derived HLS at a close N nutrient applied dose.

\subsection{Plant Growth, Quality Traits, Biomass Production and WUE}

HLS typology significantly affected the final height of the plants, as higher values were recorded in Murraya treated with Comp HLS and Digest HLS (50.5 and $47.2 \mathrm{~cm}$, respectively), whereas lower heights were measured in those treated with Leonar HLS $(38.4 \mathrm{~cm})$, and especially in the control treatment $(31.3 \mathrm{~cm})$ (Table 2). Similarly, the number of stems produced by each plant was significantly influenced by HLS. The highest amount was recorded with Comp HLS (26.8 stems plant ${ }^{-1}$ ) and the lowest one was shown for the control plants (15.8 branches plant ${ }^{-1}$ ). The number of flowers produced by every plant was also affected by the HLS typology, with the highest amount recorded with Comp HLS and Digest HLS, whereas a lower number of flowers were produced by Leonar HLS treated and the control plants (37.2 and 34.5, respectively) with no significant difference between them. The application of Comp HLS on Orange Jasmine resulted in higher fruits production (102.5 fruits plant ${ }^{-1}$ ) than that recorded for the other plants, the lowest value exhibited by the control plants ( 30.0 fruits plant ${ }^{-1}$ ). Likewise, the application of the two biowaste-derived HLS resulted in higher leaves production (148.8 and 132.6 leaves plant ${ }^{-1}$ for Comp HLS and Digest HLS, respectively) than that observed with the commercial HLS and the control (116.6 and 91.1 leaves plant ${ }^{-1}$, respectively). Leaf area was higher in plants treated with Comp HLS $\left(1730.3 \mathrm{~cm}^{2}\right)$ whereas a lower value was counted in the control plants $\left(889.1 \mathrm{~cm}^{2}\right)$.

Table 2. The effect of commercial leonardite-based and biowaste-derived (digestate and compost) HLS on plant height, number of stems, flowers, fruits and leaves, and leaf area of Orange Jasmine plants measured at 120 DAT.

\begin{tabular}{|c|c|c|c|c|c|c|}
\hline & $\begin{array}{l}\text { Plant Height } \\
\text { (cm) }\end{array}$ & $\begin{array}{c}\text { Stems } \\
{\text { (no. } \text { Plant }^{-1} \text { ) }}^{\text {(n) }}\end{array}$ & $\begin{array}{c}\text { Flowers } \\
\text { (no. Plant }^{-1} \text { ) }\end{array}$ & $\begin{array}{c}\text { Fruits } \\
\text { (no. Plant }^{-1} \text { ) }\end{array}$ & $\begin{array}{c}\text { Leaves } \\
\text { (no. Plant }^{-1} \text { ) }\end{array}$ & $\begin{array}{c}\text { Leaf Area } \\
\left(\mathrm{cm}^{2} \text { Plant }^{-1}\right)\end{array}$ \\
\hline Control & $31.3 c$ & $15.8 \mathrm{c}$ & $34.5 \mathrm{~b}$ & $30.0 \mathrm{c}$ & $91.1 \mathrm{c}$ & 889.1 c \\
\hline Leonar HLS & $38.4 \mathrm{~b}$ & $20.2 b c$ & $37.2 \mathrm{~b}$ & $53.4 \mathrm{bc}$ & $116.6 \mathrm{bc}$ & $1243.0 \mathrm{~b}$ \\
\hline Digest HLS & $47.2 \mathrm{a}$ & $20.8 \mathrm{~b}$ & $59.8 \mathrm{a}$ & $74.0 \mathrm{ab}$ & $132.6 \mathrm{ab}$ & $1387.6 \mathrm{~b}$ \\
\hline Comp HLS & $50.5 \mathrm{a}$ & $26.8 \mathrm{a}$ & $74.4 \mathrm{a}$ & $102.5 \mathrm{a}$ & $148.8 \mathrm{a}$ & $1730.3 \mathrm{a}$ \\
\hline Significance & $* * *$ & $* * *$ & $* * *$ & $* *$ & $* * *$ & $* *$ \\
\hline
\end{tabular}

***,** significant at $p \leq 0.001$, and 0.01 , respectively. Different letters within each column indicate significant differences according to Tukey's HSD test $(p=0.05)$.

In regards to biomass production (Table 3), applying Comp HLS to the plants resulted in a higher stem, leaf, and root fresh weight (FW), reaching the highest total plant FW $(129.9 \mathrm{~g})$. Digest HLS ranked as the second one (105.9 g). The control plants ranked last (82.2 g). In the same way, the Murraya plants treated with Comp HLS showed higher stem and leaf dry weight (DW), reaching the highest total plant DW (53.6 g), followed by Digest HLS (43.1 g); lower DW, singular and total, was weighed in the control (32.0 $\mathrm{g}$ for whole plant DW). 
Table 3. The effect of commercial leonardite-based and biowaste-derived (digestate and compost) HLS on fresh and dry biomass production of Orange Jasmine plants measured at 120 DAT.

\begin{tabular}{ccccccccc}
\hline & \multicolumn{4}{c}{ Fresh Weight $(\mathrm{g})$} & \multicolumn{3}{c}{ Dry Weight (g) } \\
\hline & Stem & Leaf & Root & Total & Stem & Leaf & Root & Total \\
\hline Control & $10.2 \mathrm{~b}$ & $37.3 \mathrm{~b}$ & $34.7 \mathrm{c}$ & $82.2 \mathrm{c}$ & $3.6 \mathrm{~b}$ & $14.9 \mathrm{~b}$ & 13.6 & $32.0 \mathrm{c}$ \\
Leonar HLS & $10.8 \mathrm{~b}$ & $45.1 \mathrm{ab}$ & $38.2 \mathrm{bc}$ & $94.1 \mathrm{bc}$ & $4.3 \mathrm{~b}$ & $18.6 \mathrm{ab}$ & 15.2 & $38.1 \mathrm{bc}$ \\
Digest HLS & $13.9 \mathrm{ab}$ & $49.7 \mathrm{ab}$ & $42.3 \mathrm{~b}$ & $105.9 \mathrm{~b}$ & $5.4 \mathrm{ab}$ & $20.4 \mathrm{ab}$ & 17.2 & $43.1 \mathrm{~b}$ \\
Comp HLS & $17.9 \mathrm{a}$ & $57.4 \mathrm{a}$ & $54.6 \mathrm{a}$ & $129.9 \mathrm{a}$ & $7.4 \mathrm{a}$ & $23.7 \mathrm{a}$ & 22.4 & $53.6 \mathrm{a}$ \\
Significance & $* * *$ & $*$ & $*$ & $* * *$ & $* *$ & $*$ & ns & $*$ \\
\hline
\end{tabular}

$* * * * *, *$ significant at $p \leq 0.001,0.01$, and 0.05 , respectively. Different letters within each column indicate significant differences according to Tukey's HSD test $(p=0.05)$.

Data in Table 4 show that the root length was highest in plants treated with Comp HLS, compared to plants treated with Digest HLS (31.5 and $27.7 \mathrm{~cm}$, respectively). Lower values were recorded by the Leonar HLS treated and control plants. Shoot dry matter was not affected by HLS typology, averaging a percentage of $59.0 \%$ irrespective of the treatments. Similarly, no significant differences were recorded on the root-to-shoot ratio (R/S), showing an average value of 0.78 regardless of the applied products. Water use efficiency was influenced by HLS typology. The highest value was observed for plants treated with Comp HLS, followed by the value with Digest HLS (8.9 and $6.2 \mathrm{~g} \mathrm{~L}^{-1}$, respectively). Lower WUE were recorded for Leonar HLS and the control plants (4.8 and $3.6 \mathrm{~g} \mathrm{~L}^{-1}$, respectively).

Table 4. Effect of commercial leonardite-based and biowaste-derived (digestate and compost) HLS on root length, shoot dry matter (\%), root-to-shoot ratio and biomass water use efficiency (WUE) of Orange Jasmine plants measured at 120 DAT.

\begin{tabular}{ccccc}
\hline & Root Length (cm) & Shoot Dry Matter (\%) & R/S & WUE (g L $\mathbf{~ L}^{-\mathbf{1}}$ \\
\hline Control & $20.5 \mathrm{~d}$ & $57.6 \mathrm{a}$ & 0.77 & $3.6 \mathrm{c}$ \\
Leonar HLS & $23.3 \mathrm{c}$ & $60.0 \mathrm{a}$ & 0.75 & $4.8 \mathrm{bc}$ \\
Digest HLS & $27.7 \mathrm{~b}$ & $60.1 \mathrm{a}$ & 0.88 & $6.2 \mathrm{~b}$ \\
Comp HLS & $31.5 \mathrm{a}$ & $58.1 \mathrm{a}$ & 0.73 & $8.9 \mathrm{a}$ \\
Significance & *** & $\mathrm{ns}$ & $\mathrm{ns}$ & $* * *$
\end{tabular}

***, ns significant at $p \leq 0.001$ and not significant, respectively. Different letters within each column indicate significant differences according to Tukey's HSD test $(p=0.05)$.

\subsection{Leaf SPAD Index, Gas Exchanges, Total Chlorophyll Content and Color Coordinates}

Table 5 shows that the leaf relative chlorophyll content, i.e., SPAD index, was significantly affected by HLS typology as a higher value was recorded in plants treated with Comp HLS (90.4) and secondarily with Digest HLS (81.5). A lower SPAD index was measured on leaves of Leonar HLS treated and control plants (75.2 and 63.2, respectively). Net photosynthesis (Pn) was influenced by the applied biostimulant products. The highest values were measured on Murraya leaves treated with Comp HLS and Digest HLS (7.05 and $5.60 \mu \mathrm{mol} \mathrm{CO} \mathrm{CO}_{2} \mathrm{~m}^{-2} \mathrm{~s}^{-1}$, respectively). Lower Pn was recorded in the control and Leonar HLS leaves (2.38 and $3.51 \mu \mathrm{mol} \mathrm{CO}_{2} \mathrm{~m}^{-2} \mathrm{~s}^{-1}$, respectively). Likewise, leaf stomatal conductance was higher in plants where the Comp HLS was applied $\left(0.062 \mathrm{mmol} \mathrm{m}^{-2} \mathrm{~s}^{-1}\right)$, followed by Digest HLS $\left(0.035 \mathrm{mmol} \mathrm{m}^{-2} \mathrm{~s}^{-1}\right)$. The stomatal conductance (Gs) of leaves ranged from the highest value $\left(0.062 \mathrm{mmol} \mathrm{m}^{-2} \mathrm{~s}^{-1}\right)$ for Comp HLS treated to the lowest value $\left(0.006 \mathrm{mmol} \mathrm{m}^{-2} \mathrm{~s}^{-1}\right)$ for the control plants. Similarly to the SPAD index measurements, the leaf total chlorophylls $(a+b)$ concentration was higher in plants treated with Comp HLS $\left(159.9 \mathrm{\mu g} \mathrm{cm}^{-2}\right)$ with the lowest values $\left(85.1 \mu \mathrm{g} \mathrm{cm}^{-2}\right)$ recorded in the leaves of the control plants (Table 5). 
Table 5. Effect of commercial leonardite-based and biowaste-derived (digestate and compost) HLS on leaf SPAD index, net photosynthesis (Pn), stomatal conductance (Gs) and total chlorophylls content of Orange Jasmine plants measured at 120 DAT.

\begin{tabular}{|c|c|c|c|c|}
\hline & SPAD & $\begin{array}{c}\text { Pn } \\
\left(\mu \mathrm{mol} \mathrm{CO} \mathrm{m}^{-2} \mathrm{~s}^{-1}\right)\end{array}$ & 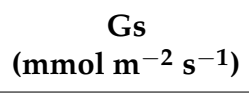 & $\begin{array}{l}\text { Total Chlorophylls } \\
\left(\mu \mathrm{g} \mathrm{cm}^{-2}\right)\end{array}$ \\
\hline Control & $63.2 \mathrm{c}$ & $2.38 \mathrm{~b}$ & $0.006 \mathrm{c}$ & $85.1 \mathrm{c}$ \\
\hline Leonar HLS & $75.2 \mathrm{~b}$ & $3.51 \mathrm{~b}$ & $0.015 \mathrm{bc}$ & $116.3 \mathrm{~b}$ \\
\hline Digest HLS & $81.5 \mathrm{a}$ & $5.60 \mathrm{a}$ & $0.035 \mathrm{~b}$ & $134.7 \mathrm{ab}$ \\
\hline Comp HLS & $90.4 \mathrm{a}$ & $7.05 \mathrm{a}$ & $0.062 \mathrm{a}$ & $159.9 \mathrm{a}$ \\
\hline Significance & $* *$ & $*$ & * & $* *$ \\
\hline
\end{tabular}

Significant differences were also recorded on leaf color coordinates (Table 6): control plants showed higher lightness (58.0), while plants treated with Digest HLS and Comp HLS evidenced lower L value (37.6 on average). Orange Jasmine treated with Digest HLS and Leonar HLS showed higher $b$ (yellowness/blueness) and Chroma (saturation) whereas the untreated plants evidenced lower values of both parameters.

Table 6. Effects of commercial leonardite-based and biowaste-derived (digestate and compost) HLS on leaf CIELAB color coordinates of Orange Jasmine plants measured at 120 DAT.

\begin{tabular}{cccccc}
\hline & $\begin{array}{c}\mathbf{L}^{*} \\
\text { (Lightness) }\end{array}$ & $\begin{array}{c}\mathbf{a}^{*} \\
\text { (Red/Green) }\end{array}$ & $\begin{array}{c}\mathbf{b}^{*} \\
\text { (Yellow/Blue) }\end{array}$ & $\begin{array}{c}\text { Chroma } \\
\text { (Saturation) }\end{array}$ & $\begin{array}{c}\text { Hue Angle } \\
\text { (Degree }\end{array}$ \\
\hline Control & $58.0 \mathrm{a}$ & $-3.0 \mathrm{ab}$ & $15.0 \mathrm{~b}$ & $16.8 \mathrm{c}$ & 161.6 \\
Leonar HLS & $43.9 \mathrm{ab}$ & $-6.4 \mathrm{~b}$ & $27.2 \mathrm{a}$ & $37.9 \mathrm{a}$ & 243.2 \\
Digest HLS & $37.7 \mathrm{~b}$ & $-0.2 \mathrm{a}$ & $26.1 \mathrm{a}$ & $33.6 \mathrm{a}$ & 295.6 \\
Comp HLS & $37.6 \mathrm{~b}$ & $-11.9 \mathrm{c}$ & $21.3 \mathrm{ab}$ & $24.5 \mathrm{~b}$ & 331.4 \\
Significance & $* *$ & $*$ & $*$ & $*$ & $\mathrm{~ns}$ \\
** $^{*}{ }^{*}$ significant at $p \leq 0.01$, and 0.05, respectively. Different letters within each column indicate significant \\
differences according to Tukey's HSD test $(p=0.05)$.
\end{tabular}

\subsection{Principal Component Analysis}

A principal component analysis (PCA) was accomplished in order to determine the interrelationship across the growth, ornamental quality, and eco-physiological parameters of the Murraya plants under different HLS treatments. The first two principal components explained $91.7 \%$ of the cumulative variance, with PC1 accounting for $82.3 \%$, and PC2 for $9.4 \%$ (Figure 1). PC1 positively correlated with the majority of the morphological and physiological parameters (plant height, stems and flowers production, leaf number, and area, fresh and dry biomass, etc.) except for the root-to-shoot ratio, lightness $\left(\mathrm{L}^{*}\right)$ and chroma component $\mathrm{a}^{*}$ to which was negatively correlated. PC2 was positively correlated with the root-to-shoot ratio, $\mathrm{L}^{*}$ and $\mathrm{b}^{*}$ only, and negatively correlated with almost all the remaining characteristics (Figure 1). PCA from the present experiment was efficient in plotting HLS treatments and the corresponding Murraya's response (Figure 1). The PCA score plot allowed the grouping of the best HLS products with regard to the different plants' performance. Digest HLS, and especially Comp HLS treatments, were respectively located on the upper and lower right quadrant and were characterized (especially Comp HLS) by higher values of most of the considered parameters; whereas Leonar HLS and the control were respectively placed on the higher and lower left quadrant, respectively, and were distinguished by the lowest morphological, productive, and qualitative performance among treatments (Figure 1). 


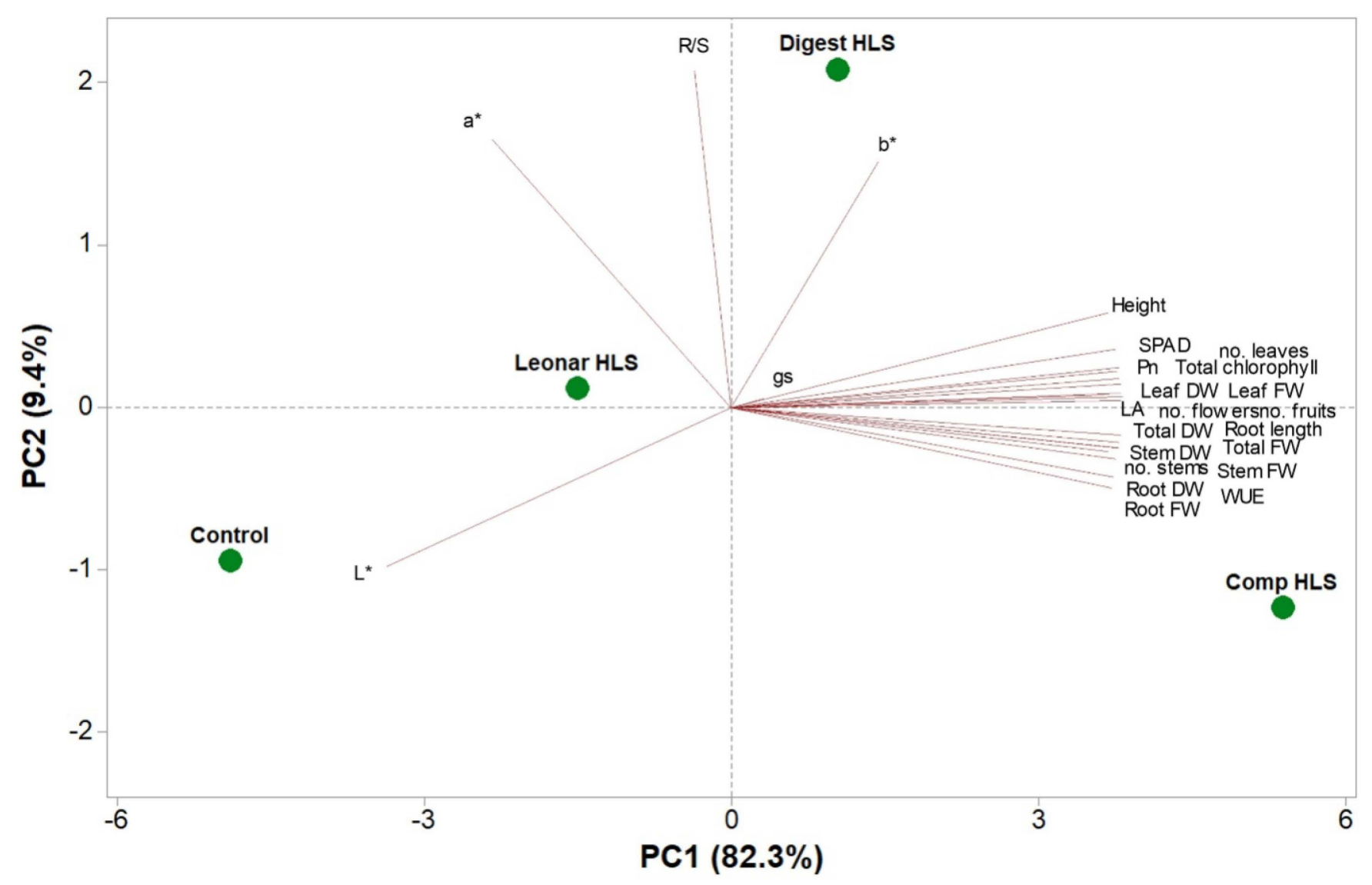

Figure 1. Principal component loading plot and scores of the principal component analysis (PCA) of biometric parameters (plant height, no. stems, flowers, fruits, leaves, leaf area: LA, stem, leaf, root total fresh weight (FW) and dry weight (DW), root length, shoot dry matter and root to shoot ratio: R/S), colorimetric parameters ( $L^{*}, a^{*}$ and $\left.b^{*}\right)$, SPAD index, total chlorophyll, leaf gas exchange (Pn: net photosynthesis and gs: stomatal conductance), and water use efficiency in Orange Jasmine plants subjected to four biostimulant treatments: untreated control, leonardite-based and biowaste-derived (digestate and compost) HLS.

\section{Discussion}

Generally, Comp HLS yielded better than or equal performance as Digest HLS. Both products showed better performance than Leonar HLS. Actually, after the application of biowaste-derived HLS, the enhancement of plant height, number of flowers and fruits, leaf production, leaf area, and biomass production was 39.9\%, 87.0\%, $111.6 \%, 35.4 \%$, $46.2 \%$, and $37.9 \%$, respectively, compared to the commercial product and to the untreated plants (Tables 2 and 3). These results have agronomical but also economic significance. HLS treatments resulted in plants with a higher aesthetic effect. This makes plants more appreciated by the consumers, consequently producing higher revenue for the nursery. The question is how well the experiment can be replicated. MBW composition is site-specific. Its variability can affect the Digest and Comp HLS composition and performance.

Municipal biowastes (MBW) are the most sustainable biowaste materials to serve as a potential feedstock for the production of value-added chemical specialties for use in different sectors of agriculture and the chemical industry [14], in place of commercial products from fossil sources. This is for two main reasons. Firstly, they are readily available worldwide in every urban settlement. They are negative cost feedstock, as their collection costs are already paid off by citizens' taxes. The solid Digest HLS and Comp HLS have been collected from the Acea MBW treatment plant located in Pinerolo, Italy. This plant is one of the most advanced installations operating on a large scale. It performs the anaerobic fermentation of MBW from separate source collection to yield biogas and the solid digestate. This product is mixed with urban green wastes and/or with the plant 
sewage sludge obtained from the microbial digestion of urban civil wastewaters and composted for 110 days. The fermented products present two further features supporting the sustainability of MWB as a potential feedstock. They contain much less water than the pristine MBW. Also, fermentation levels out differences in the chemical composition of the pristine biowaste. The results of the LIFE19 ENV/IT/000004 project [39] demonstrate that the mature anaerobic digestates and compost of MBW collected in different seasons and in three different locations in Italy, Greece, and Cyprus, do not present critical differences in composition that can significantly affect the properties and performances of the Digest and Comp HLS hydrolysates. Significant differences are however evidenced between anaerobic digestates and composts, which are reflected in significant differences of performance depending on the type of application. This is an added value in as much as it allows obtaining different products with different properties and performances for use in different applications in agriculture and in the chemical industry [14].

The ranking order of the treatments applied in this work is certainly related to the different compositions of the applied materials. It is not related to the applied product gross weight dose but is more likely related to specific organic or organo-mineral components. The applied products are a complex mixture of organic macromolecules bonded to mineral elements. This makes it rather difficult to isolate and identify the active principles responsible for the observed effects. Several authors dealing with humic or humic-like substances claim the so-called "auxin-like effect" for these products. This effect is not necessarily related to their fertilizing power or nutrient content, but the capacity of the product to affect the plant metabolism $[5,20,40]$. The hormone-like action of the two noncommercial HLS seems to result, by the way, in a higher root length recorded with Comp HLS and Digest HLS (Table 4). Higher root elongation is usually associated with an improvement of water and nutrient uptake by the plants, which in turn may be responsible for the enhanced plant growth (height, number of stems, leaf area, biomass production, and WUE) (Tables 2-4), ornamental traits (number of flowers and fruits, leaf production, and color) (Tables 2 and 6), and eco-physiological activities (chlorophyll biosynthesis, net photosynthesis, etc.) (Table 5).

We may reasonably assume that Murraya plants treated with biowaste-derived HLS were also characterized by a higher nutrient uptake, because of their better nutritional status confirmed by the higher leaf SPAD index $(+24.2 \%)$ and by the lower leaf lightness (i.e., more green-colored leaves) of Comp HLS and Digest HLS-treated plants (Tables 5 and 6). It is well known that leaf greenness is related to chlorophyll content, and the latter, involved in the photosynthetic process, is in turn associated with the presence in the leaves of adequate amounts of some important nutrients such as $\mathrm{N}, \mathrm{Mg}$ and Fe [12]. Table 1 shows that Comp HLS and Digest HLS are characterized by a higher $\mathrm{N}, \mathrm{Mg}$, and Fe content with respect to that of Leonar HLS. These ions bonded to the acid functional groups of the HLS materials have been shown to have a positive effect on photosynthesis catalyzed by HLS $[14,31,32]$. For further confirmation of the beneficial action of non-commercial HLS, Table 5 shows that Comp HLS and Digest HLS are characterized by a higher total chlorophylls $(\mathrm{a}+\mathrm{b})$ concentration in the leaves compared to those from Leonar HLS and of untreated plants.

Our hypothesis of "auxin-like effect" corresponding to biowaste-derived HLS, which is responsible for the enhanced plant growth and quality, might be eco-physiologically and biochemically evidenced with higher leaf photosynthetic activity and chlorophylls concentration, respectively, of Murraya treated with this kind of HLS (Table 5). Baglieri et al. [41] cultivated bean plants using a similar HLS obtained from the hydrolysis of exhausted tomato plants as fertilizers. They report that this product significantly enhanced nitrate reductase, glutamine synthetase, and glutamate synthase activities, and increased soluble proteins' concentration in shoots and roots, compared to the control. Based on the lack of differences between the concentrations of mineral nitrogen in the control and treated cultivation substrate, as opposed to the significant differences observed for enzymatic activity and soluble proteins' concentration in the plants, Baglieri et al. [41] concluded that 
the biopolymer acts as a plant biostimulant with a possible auxin-like effect, more than as soil fertilizer.

The results obtained from the current study on Orange Jasmine plants confirm previous outcomes achieved using the same biostimulant products, commercial and not commercial, on two different ornamental species such as Euphorbia lomi [11] and two Lantana species [12]. These authors observed in both experiments that biowaste-derived HLS are more efficient than commercial leonardite products in improving plant growth, flower production, aesthetic effect, photosynthesis, and optimizing WUE. Moreover, the same HLS (soluble hydrolysates of urban biowaste materials) were successfully used on Hibiscus-containerized plants resulting in an enhancement of biomass accumulation, relative growth rate, net photosynthesis, and SPAD index compared to a commercial biostimulant product [31,32].

In addition, the positive effects of our HLS on Murraya, which belongs to the Rutaceae family, suggest promising applications of these biostimulants on other citrus species used for fruits production (sweet orange, lemon, tangerine, etc.) and as rootstock (sour orange) for different cultivars. All these benefits deriving from the formerly obtained outcomes suggest interesting perspectives for using biowaste as feedstock for the production of powerful eco-friendly biobased agro-chemicals, which may efficiently substitute the existing fossil-based commercial products.

\section{Conclusions}

In the present experiment, the biostimulant effects of two humic-like substances obtained from municipal biowastes on Orange Jasmine potted plants were compared with those provided by a commercial leonardite-based HLS. The application of the two biowastederived HLS resulted in higher plant growth and quality traits than those obtained with the commercial HLS. The best growing and qualitative performance of plants treated with this HLS compost were due to a better nutritional status, confirmed by a higher leaf SPAD index, and total chlorophylls content, as well as by a higher photosynthetic activity of potted Orange Jasmine. Benefits provided by the application of Comp HLS, and secondly of Digest HLS, resulted in a faster growth and more rapid achievement of both the desired decorative effect and marketable size of potted Murraya as requested by the consumers; this quicker attainment often corresponds to a reduced residence time of plants in the nurseries before they sell, so to reduce costs for the growers. These outcomes allow defining smart applications of biowaste-derived HLS as effective and sustainable alternatives to the leonardite-based commercial products for nursery activities. However, additional studies would be necessary to better understand the mechanisms underlying the Murraya responses to these biostimulants, and to assess the behavior of other ornamental Citrus species to these promising HLS. Intercellular enzymatic analysis, specifically dedicated to the investigated system, will allow confirmation of the results reported for bean plants cultivated with similar HLS materials [41] and justify the positive role of N-rich biowaste-derived HLS observed in the present work.

Author Contributions: Conceptualization, G.F. and E.M.; methodology, G.F. and E.M.; software, G.F. and Y.R.; validation, G.F.; formal analysis, G.F.; investigation, G.F.; resources, G.F.; data curation, G.F.; writing-original draft preparation, G.F. and Y.R.; writing-review and editing, G.F., E.M. and Y.R.; visualization, Y.R.; supervision, G.F.; project administration, G.F.; funding acquisition, G.F. All authors have read and agreed to the published version of the manuscript.

Funding: This work was partially funded under the LIFE19 ENV/IT/000004 project.

Institutional Review Board Statement: Not applicable.

Informed Consent Statement: Not applicable.

Data Availability Statement: The datasets generated for this study are available on request to the corresponding author.

Conflicts of Interest: The authors declare no conflict of interest. 


\section{References}

1. Calvo, P.; Nelson, L.; Kloepper, J.W. Agricultural uses of plant biostimulants. Plant Soil 2014, 383, 3-41. [CrossRef]

2. Rouphael, Y.; Spíchal, L.; Panzarová, K.; Casa, R.; Colla, G. High-Throughput Plant Phenotyping for Developing Novel Biostimulants: From Lab to Field or From Field to Lab? Front. Plant Sci. 2018, 9, 1197. [CrossRef]

3. Colla, G.; Rouphael, Y. Biostimulants in horticulture. Sci. Hortic. 2015, 196, 1-2. [CrossRef]

4. Guilayn, F.; Benbrahim, M.; Rouez, M.; Crest, M.; Patureau, D.; Jimenez, J. Humic-like substances extracted from different digestates: First trials of lettuce biostimulation in hydroponic culture. Waste Manag. 2020, 104, 239-245. [CrossRef] [PubMed]

5. du Jardin, P. Plant biostimulants: Definition, concept, main categories and regulation. Sci. Hortic. 2015, 196, 3-14. [CrossRef]

6. De Pascale, S.; Rouphael, Y.; Colla, G. Plant biostimulants: Innovative tool for enhancing plant nutrition in organic farming. Eur. J. Hortic. Sci. 2018, 82, 277-285. [CrossRef]

7. Rouphael, Y.; Colla, G. Toward a Sustainable Agriculture Through Plant Biostimulants: From Experimental Data to Practical Applications. Agronomy 2020, 10, 1461. [CrossRef]

8. Petropoulos, S.A. Practical Applications of Plant Biostimulants in Greenhouse Vegetable Crop Production. Agronomy 2020, 10, 1569. [CrossRef]

9. de Pascale, S.; Rouphael, Y.; Cirillo, C.; Colla, G. Plant biostimulants in greenhouse horticulture: Recent advances and challenges ahead. Acta Hortic. 2020, 1271, 327-334. [CrossRef]

10. Ertani, A.; Pizzeghello, D.; Baglieri, A.; Cadili, V.; Tambone, F.; Gennari, M.; Nardi, S. Humic-like substances from agro-industrial residues affect growth and nitrogen assimilation in maize (Zea mays L.) plantlets. J. Geochem. Explor. 2013, 129, 103-111. [CrossRef]

11. Fascella, G.; Montoneri, E.; Ginepro, M.; Francavilla, M. Effect of urban biowaste derived soluble substances on growth, photosynthesis and ornamental value of Euphorbia x lomi. Sci. Hortic. 2015, 197, 90-98. [CrossRef]

12. Fascella, G.; Montoneri, E.; Francavilla, M. Biowaste versus fossil sourced auxiliaries for plant cultivation: The Lantana case study. J. Clean. Prod. 2018, 185, 322-330. [CrossRef]

13. Pereira, M.M.A.; Morais, L.C.; Marques, E.A.; Martins, A.D.; Cavalcanti, V.P.; Rodrigues, F.A.; Gonçalves, W.M.; Blank, A.F.; Pasqual, M.; Dória, J. Humic Substances and Efficient Microorganisms: Elicitation of Medicinal Plants-A Review. J. Agric. Sci. 2019, 11, 268-280. [CrossRef]

14. Montoneri, E. Municipal waste treatment, technological scale up and commercial exploitation: The case of bio-waste lignin to soluble lignin-like polymers. In Food Waste Reduction and Valorisation: Sustainability Assessment and Policy Analysis; Morone, P., Papendiek, F., Tartiu, V.E., Eds.; Springer: Cham, Switzerland, 2017; pp. 79-120. ISBN 9783319500881.

15. Savy, D.; Cozzolino, V.; Nebbioso, A.; Drosos, M.; Nuzzo, A.; Mazzei, P.; Piccolo, A. Humic-like bioactivity on emergence and early growth of maize (Zea mays L.) of water-soluble lignins isolated from biomass for energy. Plant Soil 2016, 402, 221-233. [CrossRef]

16. Drosos, M.; Nebbioso, A.; Mazzei, P.; Vinci, G.; Spaccini, R.; Piccolo, A. A molecular zoom into soil Humeome by a direct sequential chemical fractionation of soil. Sci. Total. Environ. 2017, 586, 807-816. [CrossRef] [PubMed]

17. Fischer, T. Humic supramolecular structures have polar surfaces and unpolar cores in native soil. Chemosphere 2017, 183, 437-443. [CrossRef]

18. Nunes, R.D.O.; Domiciano, G.A.; Alves, W.S.; Melo, A.C.A.; Nogueira, F.C.S.; Canellas, L.P.; Olivares, F.L.; Zingali, R.B.; Soares, M.R. Evaluation of the effects of humic acids on maize root architecture by label-free proteomics analysis. Sci. Rep. 2019, 9, 1-11. [CrossRef]

19. Zanin, L.; Tomasi, N.; Cesco, S.; Varanini, Z.; Pinton, R. Humic Substances Contribute to Plant Iron Nutrition Acting as Chelators and Biostimulants. Front. Plant Sci. 2019, 10, 675. [CrossRef]

20. Jindo, K.; Olivares, F.L.; Malcher, D.J.D.P.; Sánchez-Monedero, M.A.; Kempenaar, C.; Canellas, L.P. From Lab to Field: Role of Humic Substances Under Open-Field and Greenhouse Conditions as Biostimulant and Biocontrol Agent. Front. Plant Sci. 2020, 11, 426. [CrossRef]

21. Halpern, M.; Bar-Tal, A.; Ofek, M.; Minz, D.; Muller, T.; Yermiyahu, U. The Use of Biostimulants for Enhancing Nutrient Uptake. Adv. Agron. 2015, 130, 141-174. [CrossRef]

22. Nardi, S.; Ertani, A.; Francioso, O. Soil-root cross-talking: The role of humic substances. J. Plant Nutr. Soil Sci. 2016, 180, 5-13. [CrossRef]

23. Canellas, L.P.; Olivares, F.L.; Canellas, N.O.A.; Mazzei, P.; Piccolo, A. Humic acids increase the maize seedlings exudation yield. Chem. Biol. Technol. Agric. 2019, 6, 3. [CrossRef]

24. Muscolo, A.; Sidari, M.; Nardi, S. Humic substance: Relationship between structure and activity. Deeper information suggests univocal findings. J. Geochem. Explor. 2013, 129, 57-63. [CrossRef]

25. Canellas, L.P.; Olivares, F.L.; Aguiar, N.O.; Jones, D.L.; Nebbioso, A.; Mazzei, P.; Piccolo, A. Humic and fulvic acids as biostimulants in horticulture. Sci. Hortic. 2015, 196, 15-27. [CrossRef]

26. Vaccaro, S.; Ertani, A.; Nebbioso, A.; Muscolo, A.; Quaggiotti, S.; Piccolo, A.; Nardi, S. Humic substances stimulate maize nitrogen assimilation and amino acid metabolism at physiological and molecular level. Chem. Biol. Technol. Agric. 2015, 2, 5. [CrossRef]

27. Zhou, Y.; Selvam, A.; Wong, J.W. Evaluation of humic substances during co-composting of food waste, sawdust and Chinese medicinal herbal residues. Bioresour. Technol. 2014, 168, 229-234. [CrossRef] 
28. Palumbo, G.; Schiavon, M.; Nardi, S.; Ertani, A.; Celano, G.; Colombo, C.M. Biostimulant Potential of Humic Acids Extracted From an Amendment Obtained via Combination of Olive Mill Wastewaters (OMW) and a Pre-treated Organic Material Derived From Municipal Solid Waste (MSW). Front. Plant Sci. 2018, 9, 1028. [CrossRef]

29. Guo, X.; Liu, H.-T.; Wu, S.-B. Humic substances developed during organic waste composting: Formation mechanisms, structural properties, and agronomic functions. Sci. Total. Environ. 2019, 662, 501-510. [CrossRef]

30. Fascella, G.; Rouphael, Y. Growth and water use efficiency of potted Murraya paniculata as affected by irrigation system and container size. Eur. J. Hortic. Sci. 2015, 80, 81-86. [CrossRef]

31. Massa, D.; Prisa, D.; Montoneri, E.; Battaglini, D.; Ginepro, M.; Negre, M.; Burchi, G. Application of municipal biowaste derived products in Hibiscus cultivation: Effect on leaf gaseous exchange activity, and plant biomass accumulation and quality. Sci. Hortic. 2016, 205, 59-69. [CrossRef]

32. Massa, D.; Lenzi, A.; Montoneri, E.; Ginepro, M.; Prisa, D.; Burchi, G. Plant response to biowaste soluble hydrolysates in hibiscus grown under limiting nutrient availability. J. Plant Nutr. 2017, 41, 396-409. [CrossRef]

33. Spaccini, R.; Cozzolino, V.; Di Meo, V.; Savy, D.; Drosos, M.; Piccolo, A. Bioactivity of humic substances and water extracts from compost made by ligno-cellulose wastes from biorefinery. Sci. Total. Environ. 2019, 646, 792-800. [CrossRef] [PubMed]

34. Olawore, N.O.; Ogunwande, I.; Ekundayo, O.; Adeleke, K.A. Chemical composition of the leaf and fruit essential oils of Murraya paniculata (L.) Jack. (Syn.Murraya exotica Linn.). Flavour Fragr. J. 2004, 20, 54-56. [CrossRef]

35. Fascella, G.; Mammano, M.; Rouphael, Y.; Cirillo, C. Agronomical and physiological responses of containerized ornamentals to salinity induced by major nutrients. Acta Hortic. 2017, 1170, 635-642. [CrossRef]

36. Fascella, G.; Rouphael, Y.; Cirillo, C.; Pannico, A.; El-Nakhel, C.; De Pascale, S. Growth and quality response of potted ornamental shrubs under salt stress. Acta Hortic. 2020, 1296, 861-868. [CrossRef]

37. Fascella, G.; Mammano, M.; D’Angiolillo, F.; Cacini, S.; Massa, D.; Rouphael, Y. Biochar as growing substrate component for potted Murraya paniculata. Acta Hortic. 2021, 1305, 227-232. [CrossRef]

38. D'Angiolillo, F.; Mammano, M.M.; Fascella, G. Pigments, Polyphenols and Antioxidant Activity of Leaf Extracts from Four Wild Rose Species Grown in Sicily. Not. Bot. Horti Agrobot. Cluj-Napoca 2018, 46, 402-409. [CrossRef]

39. Unitelma Sapienza. La Bioeconomia Circolare Urbana: Politiche e Norme per la Transizione. Webinar at Bio-Economy Day, Rome, 27 May 2021. Available online: www.unitelmasapienza.it (accessed on 24 June 2021).

40. Canellas, L.P.; Olivares, F.L. Physiological responses to humic substances as plant growth promoter. Chem. Biol. Technol. Agric. 2014, 1, 3. [CrossRef]

41. Baglieri, A.; Cadili, V.; Monterumici, C.M.; Gennari, M.; Tabasso, S.; Montoneri, E.; Nardi, S.; Negre, M. Fertilization of bean plants with tomato plants hydrolysates. Effect on biomass production, chlorophyll content and N assimilation. Sci. Hortic. 2014, 176, 194-199. [CrossRef] 